L'émigration sud-danubienne vers la Valachie et la Moldavie et sa géographie ( $\mathrm{XV}^{\mathrm{e}}-\mathrm{XVII}{ }^{\mathrm{e}}$ siècles) : la potentialité heuristique d'un sujet peu connu

Geography of Emigration from South Danubian region to Wallachia and Moldova (15th-17th centuries): Heuristic Potential of a Little Known Matter

\title{
Lidia Cotovanu
}

\section{OpenEdition}

\section{Journals}

Édition électronique

URL : https://journals.openedition.org/ceb/4772

DOI : $10.4000 /$ ceb.4772

ISSN : 2261-4184

Éditeur

INALCO

\section{Référence électronique}

Lidia Cotovanu, «L'émigration sud-danubienne vers la Valachie et la Moldavie et sa géographie ( $x v^{\mathrm{e}}$ xvII ${ }^{e}$ siècles) : la potentialité heuristique d'un sujet peu connu », Cahiers balkaniques [En ligne], 42 | 2014, mis en ligne le 21 mai 2014, consulté le 07 juillet 2021. URL : http://journals.openedition.org/ceb/4772 ; DOI : https://doi.org/10.4000/ceb.4772

Ce document a été généré automatiquement le 7 juillet 2021

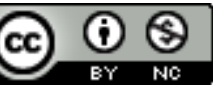

Cahiers balkaniques est mis à disposition selon les termes de la Licence Creative Commons Attribution - Pas d'Utilisation Commerciale 4.0 International. 
L'émigration sud-danubienne vers la Valachie et la Moldavie et sa géographie $\left(\mathrm{XV}^{\mathrm{e}}-\mathrm{XVII}{ }^{\mathrm{e}}\right.$ siècles $)$ : la potentialité heuristique d'un sujet peu connu

\author{
Geography of Emigration from South Danubian region to Wallachia and Moldova \\ (15th-17th centuries): Heuristic Potential of a Little Known Matter
}

\title{
Lidia Cotovanu
}

1 L'étude de la géographie de l'émigration sud-danubienne vers les Principautés de Valachie et de Moldavie est née d'une recherche plus vaste concernant les mutations identitaires qui s'opèrent d'une part chez les membres des divers groupes d'appartenance venus en contact sur le sol valaque et moldave et, d'autre part, chez les groupes de référence eux-mêmes, dont le contenu et les frontières ne cessent de bouger et de changer à la suite, entre autres, de la mobilité individuelle. C'est dans le cadre de cette recherche qu'il m'est apparu combien la géographie très précise de l'émigration balkanique vers les Principautés danubiennes pouvait nous éclairer sur bien d'autres aspects plus pointus de l'histoire des groupes socioculturels pris dans les flux migratoires que j'ai étudiés.

2 L'étude dont les résultats seront présentés ici concerne trois siècles d'émigration balkanique vers la Valachie et la Moldavie. Il s'agit d'une période comprise entre la date des premières émissions d'actes de chancellerie dans les deux pays, c'est-à-dire la seconde moitié du $\mathrm{XIV}^{\mathrm{e}}$ siècle $^{1}$, et le carrefour des $\mathrm{XVII}^{\mathrm{e}}-\mathrm{XVIII}{ }^{\mathrm{e}}$ siècles, qui précède les règnes dits phanariotes. J'ai travaillé sur un échantillon d'à peu près 4000 sujets des souverains de Valachie et de Moldavie, originaires de l'extérieur des deux pays par leur propre naissance ou par celle de leurs ascendants (il n'est pas toujours aisé de distinguer la première génération de migrants de leurs enfants et petits-enfants). Il 
s'agit plus précisément de 4000 individus de référence, les premiers de leur lignée à être mentionnés par les sources, sans compter les femmes et les nombreux descendants qui gravitaient autour d'eux. Le chiffre n'a donc qu'une valeur indicative.

\section{Immigration de proximité}

3 On remarquera d'abord que, durant la période étudiée, on a affaire à une immigration de voisinage, s'agissant d'immigrés principalement orthodoxes de Transylvanie (« Ţara Ungurească », dans les sources valaques et moldaves), à l'Ouest, du Royaume de Pologne (" Ţara Leşască »), au Nord et Nord-Est, du pays des Cosaques («părŢile căzăcești »), à l'Est, ainsi que d'outre-Danube (" Ţara Turcească », " Ţara Grecească », « Rumelia », " Ţara Sârbească »). Après avoir fait un premier point sur l'ensemble de cette immigration (princière, ecclésiastique, nobiliaire, militaire, marchande, paysanne), j'ai pu constater que les migrants d'origine sud-danubienne ont été de loin les plus nombreux. La disparition des derniers États balkaniques, à l'heure où la Valachie et la Moldavie se constituaient en nouveaux centres de pouvoir orthodoxes (XIV ${ }^{e}-\mathrm{XV}^{\mathrm{e}}$ siècles), et l'intégration graduelle de ces derniers dans le système politique et économique ottoman ont constitué des facteurs capitaux pour la dislocation d'un grand nombre de sujets chrétiens des sultans, partis pour tenter leur chance au nord du Danube et pour y faire valoir leurs compétences personnelles. Justement, à la suite de l'entrée des Principautés elles-mêmes dans l'orbite ottomane, à partir de la seconde moitié du Xve siècle, les lieux de départ des immigrés sud-danubiens n'ont pas été situés dans les régions frontalières de strict voisinage, comme cela semble avoir été le cas du côté des Royaumes de Hongrie et de Pologne. Pourtant, la géographie de l'immigration sud-danubienne ne s'étendait pas à l'ensemble de l'Empire ottoman. Il faut dire également que lorsqu'il s'agit de migrants attachés à l'orthodoxie d'expression grecque, leur espace d'origine ne se confond pas nécessairement avec le territoire nationalisé et culturellement homogène de la Grèce actuelle, tout comme leur(s) appartenance(s) collective(s) grecque(s) (linguistique, confessionnelle, juridictionnelle) ne se confond(ent) pas avec celle d'aujourd'hui (nationale).

Il a été possible d'établir la carte de ladite immigration en passant par trois procédures d'identification de l'origine géographique des migrants. J'ai d'abord dressé la liste des immigrés dont la localité ou la région plus élargie d'origine est déclarée de manière explicite par les sources ou peut être facilement déduite ${ }^{2}$.

Tableau : Localité d'origine déclarée des migrants

\begin{tabular}{|l|l}
\hline Espaces sud-slaves & Espaces de langue liturgique grecque
\end{tabular}




\begin{tabular}{|c|c|}
\hline $\begin{array}{l}29 \text { individus: Croatie, Monténégro, Bosnie, } \\
\text { Serbie } \\
91 \text { individus: Kiprovac, Nikopolis, Rusciuc } \\
\text { (Ruse), Cernavoda (Cerven), Arvanitochori de } \\
\text { Răzgrad, Dârstor (Silistra), Sofia, Tărnovo, } \\
\text { Varna } \\
\text { (localités actuellement situées en Bulgarie) }\end{array}$ & 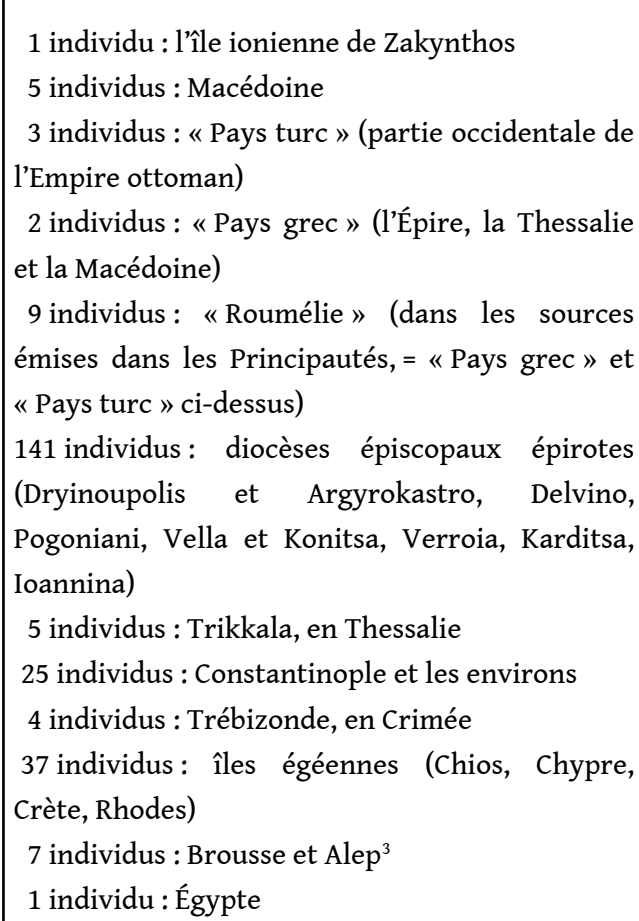 \\
\hline$=120$ individus & $=240$ individus \\
\hline
\end{tabular}

$5 \quad$ Le but a été de déceler des spécificités anthroponymiques, correspondant à des espaces plus ou moins précis, ce qui m'a permis de mieux dessiner la géographie de l'immigration sud-danubienne. La liste ci-dessus est celle des régions et des localités obtenue, telles qu'elles sont mentionnées par les sources consultées, en allant d'ouest en est.

6 Il est évident que la plupart des immigrés arrivaient des régions sud-slaves ${ }^{4}$ et des régions continentales de langue liturgique et de communication grecque, avec une forte concentration dans l'Épire historique, aujourd'hui coupée en deux par la frontière

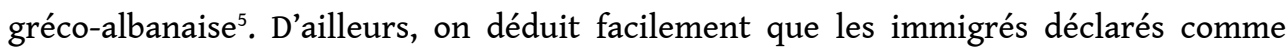
étant arrivés du «Pays turc » ou de «Roumélie » étaient plus précisément originaires de quelque part en Épire, à en juger d'après leurs noms caractéristiques de ces régions : Cârstea Ghenovici (fils de Ghinea ; son fils s'appelait Ghionea), Ghinea Tुucala et son frère Arsenie, mais aussi Iane Hadâmbul (employé dans la maison du prince de Moldavie Vasile Lupu Coci, lui-même issu d'une lignée épirote) et son neveu Ianachi, ainsi qu'un certain Mecula. Pour le dernier, on sait que son fils était le neveu des marchands Pepano de Pogoniani ${ }^{6}$.

7 Ces chiffres ne sont pas définitifs, vu qu'en réalité les lieux d'origine répertoriés correspondent souvent à des points de départ et non pas à des lieux de naissance ou d'origine lignagère plus lointaine. C'est le cas notamment des localités situées en territoire slave (mais canoniquement dépendantes du Patriarcat de Constantinople): Varna, Sofia, Tărnovo, Arvanitochori, Dârstor, Cernavoda, Rusciuk, Nicopolis, les cinq dernières se trouvant tout près du Danube, d'un bout à l'autre du fleuve qui formait la frontière de la Valachie. Les noms personnels de beaucoup d'immigrés arrivés de ces localités, ainsi que leurs signatures autographes grecques ou encore le nom collectif 
«Albanais » (« arbănaş »), qui leur est assigné individuellement ou collectivement par les contemporains ${ }^{7}$, indiquent qu'ils venaient de plus loin et cela ne pouvait être que des régions épirotes et des environs, régions à forte concentration de population orthodoxe. L'illustration de ce fait nous est fournie par le cas de la famille Coci, d'où est issu le prince de Moldavie Vasile Lupu (1634-1653). Originaires d'Épire, mais installés, au cours du $\mathrm{xVI}^{\mathrm{e}}$ siècle, dans la région bulgare de Razgrad, près du Danube, les Coci et les leurs - parents et compatriotes - ont colonisé le village qui a pris le nom suggestif d'Arvanitochori (le village des Albanais, en roumain Arbănaşi et en turc Arnautköy) ${ }^{8}$. À la même époque vit le jour un autre village d'Arvanitochori près de la ville bulgare de Tărnovo, de même colonisé par des Épirotes arrivés pour la plupart de la ville de Moschopolis (aujourd'hui Voskopolie, en Albanie du Sud) ${ }^{9}$. Évidemment, la ville de Tărnovo elle-même, tout comme Varna et Sofia, devait compter de nombreux habitants épirotes nouvellement arrivés pour des raisons commerciales ou militaires. Il semble donc plus plausible que les frères « albanais » Racotă, spécialisés dans les faits d'armes, et leur mère Chirą̧a soient arrivés en Valachie de la Tărnovo bulgare que du petit village homonyme de Thessalie ${ }^{10}$. Le néo-martyre Nicola de Ioannina, quant à lui, vint s'installer en Valachie, au milieu du $\mathrm{xVI}^{\mathrm{e}}$ siècle, après avoir exercé le métier de cordonnier à Sofia ${ }^{11}$. Quelques décennies auparavant, vers 1520 , le frère de l'un des nouveaux ktitors (fondateurs) du monastère Ste-Anastasia-Pharmakolytria de Chalcidique, originaire de la ville d'Arta, avait pris lui aussi le chemin de la Valachie et il choisit de s'installer dans un premier temps près de Nikopolis ${ }^{12}$.

8 Pour ces raisons - séjours passagers ou colonisations collectives de localités situées en territoire anciennement bulgare par des «Albanais»-, on tiendra ceux-ci pour originaires de régions épirotes et des contrées avoisinantes. C'est du moins le cas des Coci et des leurs, installés à Arvanitochori (supra), celui des Racotă de Tărnovo (supra) et celui des « Albanais » de Cernavoda, localité située près de la ville bulgare de Rusciuc (Ruse, sur le Danube) ${ }^{13}$. Dumitraşco, grand trésorier de Valachie (signe $\left.\Delta \eta \mu \eta \tau \rho \alpha \sigma \kappa o \varsigma\right)$ et son frère Cara Hagi Hasan, marchand de Dârstor (Silistra), puis les marchands Chiriac

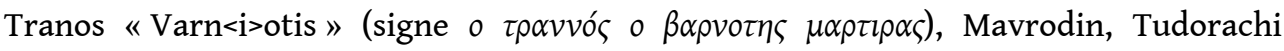

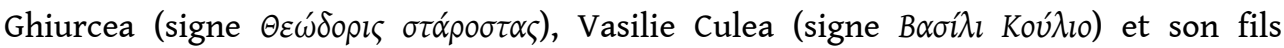

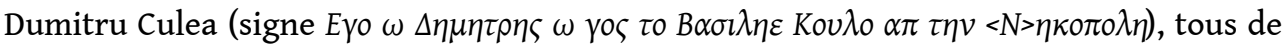
Nikopolis, ou encore Manul Sofileu (signe $\mu \alpha v \circ \varsigma \sigma \tau \alpha \rho \omega \sigma \tau \alpha \varsigma$ ) et son neveu Necula

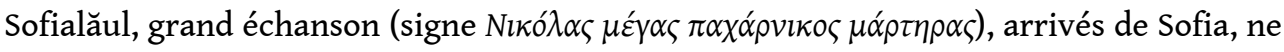
semblent pas eux non plus être natifs ou issus de lignées originaires desdites villes, vu leurs signatures grecques, leurs liens de parenté ou leur entourage professionnel et de voisinage qui renvoient à des espaces de langue liturgique grecque. Dumitraşco grand trésorier était le gendre de Hrizea (Rizos) grand palatin de Bălteni (signe Hrizea vel

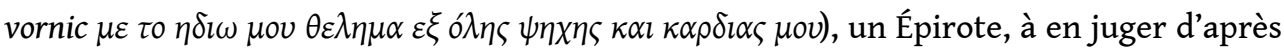
ses familiares (employés et subalternes attachés à sa maison) ${ }^{14}$. Chiriac Tranos dit "Varn<i>otis » de Jassy n'était autre que le filleul de Gheorghe épicier d'Argyrokastro, celui-ci étant connu pour sa donation envers le monastère de Drianou, situé dans son diocèse d'origine ${ }^{15}$. La situation est semblable dans le cas des marchands arrivés de villes plus lointaines, telle Brousse, où l'on retrouve les traces de réseaux commerciaux ayant pour point de départ les régions épirotes. C'est du moins le cas du marchand Zota/Zotos (nom d'étymologie albanaise), qui signe du nom de « Brousiotis » (repris par le document roumain sous la forme «Braşoti»), indiquant ainsi ses liens avec la ville

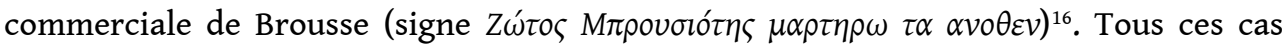


peuvent être comparés avec celui des marchands Ioannis Kazolis, Necula et Stoica de Valachie (xvII siècle), mentionnés comme étant des "Vénitiens» («veneŢianul»), d'après la ville où ils déployaient leurs activités commerciales ${ }^{17}$.

Compte tenu des particularités évoquées ci-dessus, on obtient une redistribution des chiffres évoqués auparavant, soit :

- 52 individus seulement arrivés des régions sud-slaves;

- 209 individus arrivés d'Épire et des environs (soit $87 \%$ du total des immigrés arrivés des régions de langue grecque, y compris Constantinople).

On ajoutera à cette liste, modeste mais déjà parlante, les individus dont le lieu d'origine n'est pas attesté par les sources. En revanche, leur nom personnel est accompagné du nom collectif «le Serbe » ("sârbul » "sârbean »), ou "l'Albanais » (" arbănaşul »), indiquant forcément, dans un cas, des immigrés arrivés de régions sud-slaves et, dans l'autre, des immigrés arrivés de régions de langue grecque, qui ne pouvaient être situées qu'en Épire et dans les contrées colonisées par des Épirotes. On obtient ainsi un total de :

- 141 individus arrivés des régions sud-slaves et 224 individus originaires d'Épire.

11 Effectivement, cette première liste d'immigrés, établie en fonction de leur lieu d'origine et des noms collectifs «le Serbe " et "l'Albanais » accolés à leurs noms personnels, révèle des spécificités anthroponymiques correspondant plus ou moins à la "slavité ", l'« albanité » et la " grécité » linguistique des deux aires culturelles de départ (slave et grecque). À commencer par les "Serbes" (il faut savoir qu'à l'époque étudiée les sources valaques et moldaves appelaient tous les slaves balkaniques du nom de "Serbes $»^{18}$ ), les noms qui leur sont caractéristiques et qui sont, en effet, aussi rares dans les régions de langue grecque qu'en Valachie et en Moldavie, sont les suivants :

Gaşpar (porté par les Dalmates), Iovan, Marco, Novac, Peia, Petco, Poznan, Raine, Stanco, Stoian, Tatu(l), Velicico, Voico, Vuc, Vucina, Vucomir.

On peut allonger cette courte liste de quelques autres noms d'usage habituel sud-slave et plutôt rares dans les Principautés danubiennes :

Babici, Baico, Balaci, Balş, Boico, Calcio (Calciul), Calin, Cernat, Cernica, Chiajna, Coia, Coico, Dabija, Dârjan, Despot (Dispot), Ghizdav, Goran, Ianoş, Jivco, Lubaş (Liubaş), Mara, Milco, MileŢ, Miloş, Mira, Mirco, Miroslav, Obredi, şişman (şuşman), StraŢimir, Tatomir, Vucaşin, Zlate, etc. ${ }^{19}$

La liste des immigrés appelés de ces noms spécifiques sud-slaves se monte à 129 individus environ et, ensemble avec les 141 individus répertoriés précédemment, ils représentent $6,75 \%$ du total des individus compris dans mon échantillon de recherche.

La conclusion qu'on peut tirer de ce chiffre, qui n'a qu'un rôle indicatif, porte sur l'arrivée continue des migrants originaires des régions sud-slaves au cours des trois siècles étudiés $\left(\mathrm{xv}^{\mathrm{e}}\right.$-XVII ${ }^{\mathrm{e}}$ siècles) ${ }^{20}$. Ils appartenaient à toutes les catégories sociales (grands boyards et serviteurs princiers dotés ou non d'offices, marchands, militaires, membres du clergé, notables villageois). Les chiffres recueillis sont loin d'illustrer les vraies proportions de l'immigration sud-slave et cela à cause de l'écriture slavonne commune aux régions de départ et aux pays d'arrivée (le slavon y était la langue officielle), de la diffusion d'un stock anthroponymique commun (d'étymologie slave, mais aussi roumaine) sur les deux rives du Danube et de l'adaptation des noms importés aux usages phonétiques et morphologiques locaux, ce qui nous empêche de distinguer, dans l'espace d'accueil, les immigrés des autochtones. 

régions de langue grecque. Si l'on compare les noms personnels figurant sur la liste des 224 immigrés arrivés d'Épire avec ceux des 25 arrivés de Constantinople et des 37 venus des îles égéennes (des marchands pour la plupart), on constate aisément des spécificités anthroponymiques chez les uns et chez les autres. L'influence italienne sur les sujets vénitiens et génois est palpable : Amirali, Amoroso, Andrea, Baptista, Domestico, Dominicus, Esther, Leoninos, LorinŢ, LucreȚia, etc.

Quant aux Constantinopolitains (dits " Ţarigrădeni ", d'après l'appellation slave de la ville, " Ţarigrad»), on y trouve des Cantacuzène et des Paléologue dont les noms de famille sont, en effet, liés historiquement à la capitale de Byzance ${ }^{21}$. Or, les habitants de Constantinople n'étaient que rarement des vrais et anciens citadins. Tous les immigrés déclarés par nos sources comme étant de «Țarigrad» et qui, en règle générale, arrivaient dans les Principautés dans la suite des princes nommés à Istanbul n'étaient pas natifs ou issus de familles résidantes de longue date dans la capitale ${ }^{22}$. Le marchand Ghioca dit "le Constantinopolitain ", à en juger d'après l'allure albanaise de son nom, n'était certainement pas un citadin de souche, mais le négoce ou une quelconque autre activité l'avait amené à s'y installer, à l'instar du futur prince de Moldavie et de Valachie Gheorghe Ghica (1658-1659, 1659-1660), qui était passé par Constantinople avant d'arriver à Jassy pour des raisons commerciales ${ }^{23}$. Tel est le cas d'un autre « Arnaut » de Constantinople, le boulanger Dimos, parti s'installer en Valachie, en 1667, auprès de ses proches parents qui y habitaient déjà ${ }^{24}$. Le grand échanson de Valachie

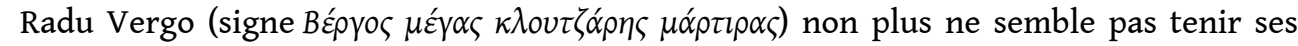
racines lointaines du village de Ceatalgea, près de Constantinople, à en juger d'après son prénom slave ${ }^{25}$. Même les Cantacuzène (ou du moins une branche de la famille) détenaient, au xvi ${ }^{\mathrm{e}}$ siècle, leur fief à Anchialos, au bord de la mer Noire, dans la région (actuellement bulgare) de Sozopolis ${ }^{26}$, alors que d'autres membres de la famille siégeaient à Trikala, en Thessalie ${ }^{27}$, et que d'autres encore s'étaient installés, au $\mathrm{XV}^{\mathrm{e}}$ siècle, dans la Serbie des derniers Branković, leurs parents par alliance ${ }^{28}$. Un des leurs, Dionysios Rhallys Paléologue, est devenu métropolite de Tărnovo à la fin du $\mathrm{XvI}^{\mathrm{e}}$ siècle $^{29}$.

Une fois établies ces spécificités anthroponymiques, on peut procéder à l'allongement de la liste des immigrés présentant la même gamme de noms personnels, mais dont le lieu d'origine n'est pas indiqué expressément par les sources consultées. On tiendra tous ceux-ci pour originaires de régions de langue grecque qui ne dépassaient pas la Thessalie, au Sud, et la Macédoine, à l'Est.

On y ajoutera encore les porteurs d'autres noms d'étymologie ou d'usage albanais que ceux déjà mentionnés : 
Araniti, Arap, Bucur, Floca, Gole, Golem, Manta, Mazarachi, Muzachi, Paindur, Spata, Tsana, Trahano.

Ceux appelés de noms caractéristiques des régions balkaniques de langue grecque plus généralement, noms qui ne figurent pas parmi ceux recensés ci-dessus :

Andoca, Anghelet, Arghiri, Armega, Caloian, Chefa (Chifu), Chiriac (Chirica), Chisar, Ciumelita, Cuzea (Cuza), Diamandi, Drosul (Drosea), Grama, Hagi, Hrizea (<Rizos), Iacomi, Iamandi, Iana, Lascăr (LaŢcar), Lefter, Machidon, Mecul (Mecula), Meiută (<Maiotas), Margarit, Matraca, Mavros, Mavrodin, Mavrichi, Moscu, Nacul (<Nakos), Pantazi, Pardos, Paros (Para, Parus, Pera), Păun (<Pagonis), Parasca, Porfir (Prohir), Rustea, Sarul, Sinadino, Sotir, Stavro (Stavăr), Stelea, Sterie, Strat(i), SuŢu, Trandafir, etc. ${ }^{30}$

Les immigrés chrétiens appelés de prénoms ou de noms de famille d'étymologie turque :

Alagoz, Azap, Baba (Babachi), Burnar, Burnaz, Buta, Cara, Caracaş, Caragea, Caraghioz, Caraochi, Caraman, Caramazache, Cehan, Celebi, Colceac, Cuciuc, Cuiumgi, Curt, Deli (Dealeu, Dilea), Hadâmbul, Hamza (Amza), Hurmuz, Iarali, Malcoci, Momce, Pârvana (<Pervanà), Răgep, Sultan, Talapie, Veisa, etc. ${ }^{31}$

Ou encore ceux portant des noms chrétiens, mais étant désignés d'un nom collectif «turcul» (le Turc); ce sont les noms de leurs proches parents (Caloian, Dima, Ghioca, Leca, Micu, Stoica, etc.) qui indiquent que là encore on a affaire à des immigrés dont le lieu d'origine ne dépassait pas la Macédoine, à l'Est, et la Thessalie, au Sud ${ }^{32}$.

On estimera d'autant plus comme étant originaires d'espaces d'interaction et de fusion socioculturelle gréco-slave les immigrés aux noms slaves et roumains qui apposaient leur signature en grec :

Drăghici, Drăgoiu, Dragosin, Dârjan, Lepădat, Neagul, Nenciul, Radul, Stan, Stanciul,

Stoia, Stoian, Stoica, etc. ${ }^{33}$

Si l'on compte tous les immigrés portant les noms ci-dessus ${ }^{34}$, en plus de ceux portés par des immigrés arrivés d'Épire et des environs (224 personnes de référence), on obtient un nombre supplémentaire d'à peu près 2000 individus, ce qui représente $55 \%$ du total des immigrés recensés. Le pourcentage obtenu indique une tendance nette à l'immigration depuis les régions balkaniques de langue grecque, avec toujours une forte concentration de migrants originaires des régions épirotes ${ }^{35}$. On conclura que d'autres immigrés, aux noms tirés du calendrier orthodoxe et souvent désignés comme étant des «Grecs » («grecul », "greci »), doivent s'inscrire dans cette même tendance qu'on appellera immigration de proximite ${ }^{36}$.

Après avoir entrepris cette minutieuse enquête, je me suis aperçue que la géographie de l'immigration correspondait parfaitement à celle des donations religieuses orientées cette fois-ci depuis la Valachie et la Moldavie vers l'extérieur (exceptés les lieux hautement symboliques de l'orthodoxie : Athos, Sinaï, Patriarcats grecs) :

- 123 (41 \%) actes de donation orientés vers des espaces sud-slaves (Croatie, Serbie, Bulgarie, Macédoine),

- 162 (53\%) actes de donation orientés vers des espaces continentaux de langue liturgique grecque (Macédoine, Épire, Thessalie),

- 19 (6\%) actes de donation seulement orientés vers d'autres espaces de langue grecque (Constantinople, Péloponnèse, Crimée, Crète, Chios).

Précisons que $37 \%$ des donateurs étaient membres de maisons princières (princes, princesses et autres proches parents des souverains) ${ }^{37}$ et $63 \%$ étaient issus de la haute et de la petite noblesse ou encore de la classe marchande et des rangs du clergé, pour la 
plupart originaires des lieux secourus. Dans le cadre de cette dernière catégorie de donateurs, on a affaire, je l'ai montré ailleurs, à une tendance manifeste de retour symbolique vers l'espace d'origine ${ }^{38}$. On a ici la confirmation, par une autre filière d'investigation, de ce que j'ai appelé auparavant immigration de proximité.

\section{Immigration et comportements identitaires} utile pour la compréhension des comportements identitaires manifestés par les membres des groupes de référence venus en contact sur le sol valaque et moldave: «Serbes», «Bulgares», «Albanais», «Valaques», "Grecs», tous étant des Orthodoxes, sauf exception? Voici quelques brèves suggestions à ce propos, faute d'espace pour en dire plus.

La géographie de l'immigration qui, on l'a vu, correspond à la géographie des donations religieuses provenant de Valachie et de Moldavie, correspond également à la géographie des autonomies juridico-administratives attribuées par les sultans à maintes communautés chrétiennes demeurant entre l'Adriatique, la Macédoine et la Thessalie, en échange de services militaires, économiques et administratifs pris en charge pour le compte de l'État ottoman ${ }^{39}$. Il s'agit de communautés (rurales, montagnardes, urbaines) qui avaient reçu le droit d'auto-administration et dont les membres, dans certains cas, étaient soumis à des responsabilités fiscales collectives, de sorte que c'était à leurs chefs et juges communautaires (prélats, notables communaux ou chefs de corporations) d'en faire état aux agents du fisc ottoman ${ }^{40}$. Il est fort probable que l'autonomie administrative et judiciaire de ces communautés et, le cas échéant, leurs responsabilités fiscales collectives, laissaient à leurs membres une certaine liberté de mouvement, consentie par les leurs, permettant principalement aux jeunes célibataires de tenter leur chance dans les Principautés et ailleurs, via le commerce ou les armes ${ }^{41}$. Les tentatives ottomanes de supprimer lesdits privilèges à des communautés qui avaient perdu au fil du temps leur importance stratégique pour l'Empire n'auraient fait qu'inciter davantage leurs membres à partir ${ }^{42}$. Dès lors, on se demandera s'il ne faut pas voir dans la liberté de mouvement et de déplacement à distance des sujets chrétiens du sultan l'effet, du moins en partie, de ces autonomies locales. C'est une piste à explorer par les futures recherches. Du reste, outre la proximité géographique et les autonomies locales balkaniques (leur émission et/ou leur suppression), il faudra rechercher les causes de l'émigration préférentielle des chrétiens sud-slaves et grecs continentaux vers les Principautés dans les traditions de déplacement vers les deux pays danubiens, traditions qui se sont formées dans la longue durée, via les réseaux de solidarités familiales, de voisinage et socioprofessionnelles ${ }^{43}$.

L'hypothèse d'un lien qui existerait entre la géographie des autonomies locales balkaniques, celle de l'émigration vers les Principautés et celle des donations orientées depuis les deux pays danubiens vers le Sud, acquiert encore plus d'importance, car elle nous met en liaison avec la géographie des régions balkaniques qui ont abrité par le passé - certaines le font encore de nos jours - des populations valaques (je ne m'arrêterai pas ici sur le sens linguistique, juridique et socioprofessionnel de ce nom collectif). Disséminées entre les côtes adriatiques, la Macédoine, la Thessalie et l'Étolo-Acarnanie, les communautés valaques (mais pas seulement) ont bénéficié d'autonomies administratives et de privilèges fiscaux de la part du conquérant ottoman, en vertu du 
droit spécifique appelé jus valachicum (en turc ottoman adet-i eflaqyye, adet-i eflaqyye üzere), conservé depuis les temps reculés de Byzance et du Royaume de Serbie (en slave vlaški običaj, vlaški zakon); les travaux de Nicoară Beldiceanu et d'autres spécialistes en histoire ottomane le montrent amplement ${ }^{44}$. On supposera que les Valaques ont émigré en nombre important depuis les espaces sud-slaves et grecs vers les Principautés, suite à la fondation des deux États et, plus tard, suite à l'intégration des deux pays dans le système politique et économique ottoman. Je tire mon argument du silence quasi total des sources valaques et moldaves au sujet des immigrés valaques balkaniques (je me réfère ici aux cas individuels; mais les mentions collectives restent rares elles aussi). Sur les trois siècles étudiés, les sources valaques et moldaves consultées font part d'un seul «Cutsovalaque $»^{45}$. Il n'y avait pas besoin d'apporter des précisions au sujet de leur appartenance collective primaire, le vocabulaire lié à cela étant commun aux arrivés et aux accueillants. Les uns et les autres étaient des Valaques, au regard des Autres; les uns et les autres étaient des Roumains/Aroumains pour Soi-même ${ }^{46}$.

"Grecs", "Valaques» et "Albanais », originaires d'Épire, de Thessalie et de Macédoine, arrivaient d'espaces balkaniques qui avaient pour caractéristique la diglossie (vernaculaires grecs/grec savant) et le multilinguisme (langue domestique/langue de communication extracommunautaire/langue de culture). On a affaire à des sujets chrétiens des sultans qui partageaient des appartenances collectives multiples, d'ordre linguistique notamment et culturel plus généralement, mais aussi d'ordre spatial (origine d'un espace politique, géohistorique, juridictionnel, administratif). Un Albanais d'Épire était aussi un Grec, voire un Romaios, par son attachement à l'Église grecque de Constantinople et à la culture dominante de celle-ci ${ }^{47}$. Par contre, un habitant de Ioannina, Grec qu'il entendait être par son vernaculaire familial et par son attachement à l'Église grecque, n'était pas un Grec Constantinopolitain (particulièrement stigmatisé dans les Principautés danubiennes), ni un Grec crétois, attaché au monde vénitien. Les Épirotes étaient donc des Grecs, mais pas seulement. Ceci devrait nous aider à comprendre ce qui pendant longtemps est apparu aux historiens comme un paradoxe : le fait que, lors des révoltes anti-grecques qui ont éclaté dans les Principautés au cours du XvII ${ }^{\mathrm{e}}$ siècle, les meneurs des discours et des actions ont été souvent des allogènes grécophones eux-mêmes, tels Cârstea Ghenovici, grand palatin, Leca, grand spathaire de Leurdeni, Nica, grand logothète de Corcova ou encore Vasile Lupu Coci, futur prince de Moldavie (1634-1653), tous originaires d'Épire ${ }^{48}$. Ce qui caractérisait ces acteurs était notamment la possibilité de choisir parmi leurs appartenances collectives multiples et de mettre en avant la plus convenable, selon les circonstances et les intérêts à défendre ${ }^{49}$. En leur qualité de sujets des souverains valaques ou moldaves et vu aussi le climat local hostile à la grécité institutionnelle constantinopolitaine, structurée autour du Patriarcat œcuménique, et à la grécité socioculturelle tout court, il était dans leur intérêt personnel d'afficher tout autre appartenance collective que l'appartenance grecque. Pour Vasile Lupu de Moldavie, dans sa quête du trône moldave, c'étaient les autres, les ennemis du pays qui étaient des $" G r e c s »^{50}$. Lui, qui allait pourtant se comporter par la suite en « empereur » et grand protecteur de l'Église grecque ${ }^{51}$, misait sur son appartenance juridique aux lieux d'accueil (c'est à ce titre qu'il a visé et occupé le trône moldave), mais également sur son appartenance albanaise - c'est ainsi que les contemporains l'ont connu ${ }^{52}$. Aux yeux des paysans moldaves il fut pourtant un "Grec », aux dires du chroniqueur Miron $\operatorname{Costin}^{53}$, tout comme il l'était pour son successeur au trône moldave, Gheorghe ştefan (1653-1657) ${ }^{54}$. Quant aux immigrés sudslaves, ils étaient de toute façon du «bon » côté de la médaille. 
31 En résumé, au-delà de la religion, qui était l'ordre légitimateur du pouvoir politique (les princes de Valachie et de Moldavie étaient des élus " par la grâce de Dieu »), il n'y avait pas de principe de droit qui aurait tranché en faveur de telle ou telle appartenance collective des individus (linguistique ou géospatiale) ${ }^{55}$. Seuls leur allégeance au souverain des lieux et l'établissement du domicile fiscal sur place comptaient au regard de l'autorité légitime ; je tâcherai de développer ailleurs cet aspect. Du coup, ce vide juridique laissait aux intéressés la possibilité de mettre en avant l'appartenance (originaire ou acquise) convenable, si les circonstances l'exigeaient. Le cas des migrants balkaniques des Principautés danubiennes, intégrés dans les plus hautes sphères locales de pouvoir, nous apporte une belle illustration, qui mérite qu'on lui prête plus d'attention à l'avenir.

\section{BIBLIOGRAPHIE}

Aftodor, Stefan, (2011) “The land estate of boyar Hrizea from Bălteni”, Istros XVII, pp. 235-257. Andreescu, Stefan (1997), «Exarhul patriarhal Nichifor Dascălul, cneazul Constantin Vasile de Ostrog şi Mihai Viteazul», dans idem, Restitutio Daciae, III, Studii cu privire la Mihai Viteazul, Bucarest, p. 81-113.

Apetrei, Cristian Nicolae, (2012), «Marele negustor grec din Moldova (cca 1570-1620). Un profil colectiv din perspectivă braudeliană », Revista istorică XXIII/1-2, p. 65-84.

Barbu Violeta, (2010), « Les Arbanassi : un réseau marchand aux frontières de l'Empire ottoman au début du XVII ${ }^{\mathrm{e}}$ siècle », Études balkaniques XLVI/1-2 (Sofia 2010), p. 206-222.

Beldiceanu Nicoara, (1957) «La région de Timok-Morava dans les documents de Mehmed II et de Selim I », Revue des études roumaines III-IV (1957), p. 111-129.

Beldiceanu Nicoara, (1966), « Sur les Valaques des Balkans slaves à l'époque ottomane (1450-1551) », Revue des études islamiques 4 (1966), p. 83-132.

Beldiceanu Nicoara, (1975), « Les Valaques de Bosnie à la fin du XV siècle et leurs institutions », Turcica VII (1975), p. 122-134.

Beldiceanu Nicoara, (1981), « Populations chrétiennes et franchises dans l'Empire ottoman », dans Lo Stato e il potere nel Rinascimento, Mélanges Federico Chabod, Perugia, p. 101-111.

Beldiceanu Nicoara, (1990), « Les Roumains des Balkans dans les sources ottomanes », Études roumaines et aroumaines, p. 11-19.

Beldiceanu Nicoara, Beldiceanu-Steinherr Irène, (1955), « Quatre actes de Mehmed II concernant les Valaques des Balkans slaves », Südost-Forschungen XXIV (1955), p. 103-118.

Beldiceanu Nicoara, Beldiceanu-Steinherr Irène, P.ş. Năsturel, (1988) « Les recensements ottomans effectués en 1477, 1519 et 1533 dans les provinces de Zvornik et d'Herzégovine », Turcica XX (1988), p. 160, 164.

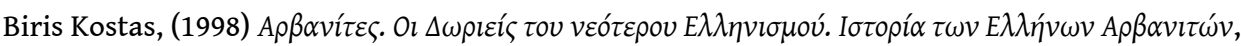
Athènes. 
Camariano-Cioran Ariadna, (1984) L'Épire et les Pays roumains, Ioannina.

Cantacuzino Ion, Cazacu Matei, (2001) « Généalogie et empire. Les Cantacuzène de l'époque byzantine à l'époque ottomane ", dans L'empereur hagiographe. Culte des saints et monarchie byzantine et post-byzantine, Bucarest : éd. P. Guran, B. Flusin, p. 294-308.

Cazacu Matei, (1996), « Stratégies matrimoniales et politiques des Cantacuzène de la Turcocratie (XV'-XVI ${ }^{\mathrm{e}}$ siècles) », Revue des études roumaines XIX-XX (1995-1996), p. 157-181.

Cazacu Matei, (1999) « La chancellerie des Principautés valaque et moldave (XIVe-XVIII ${ }^{\mathrm{e}}$ siècles) », dans Kanzleiwesen und Kanzleisprachen im östlichen Europa, Vienne : éd. Chr. Hannick, p. 87-127.

Cazacu, Matei, (2012), «Despre câteva vechi biserici bucureștene din veacurile XVI - XVIII», dans Aut viam inveniam aut faciam. In honorem ştefan Andreescu, Jassy: éd. O. Cristea, P. Zahariuc, Gh. Lazăr, p. 469-492.

Cicanci Olga, (1981) Companiile greceşti din Transilvania şi comerŢul European în anii 1636-1746, Bucarest.

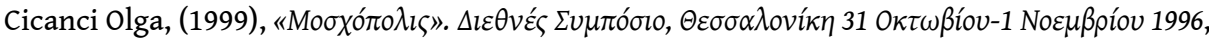
Thessalonique.

Ciobanu Stefan, (1944), « Informations sur la Valachie au XVI e siècle dans une œuvre hagiographique bulgare », Balcania VII/1 (1944), p. 121-151.

Cotovanu Lidia, (2012) «Chi "finanziò" gli studi a Padova di siniscalco Costantino Cantacuzeno (1667-1669)?», in La storia di un ri-conoscimento : i rapporti tra l'Europa Centro-Orientale e la Panisola italiana dal Renascimento all'Età dei Lumi, Brăila-Udine : éd. Cr. Luca et G. Masi, p. 291-328.

Cotovanu Lidia, (2009), « Le diocèse de Dryinoupolis et ses bienfaiteurs de Valachie et de Moldavie. Solidarités de famille et traits identitaires multiples (xvI ${ }^{\mathrm{e}}$ siècles) », in ContribuŢii privitoare la istoria relaŢiilor dintre Ţările Române şi Bisericile Răsăritene în secolele XIV-XIX, Jassy : éd. P. Zahariuc, p. 240-257.

Crina-Mihaela Rafaela, (2008), Documentele epocii brâncovenești în colecţiile Muzeului Municipiului București, Bucarest, $n^{\circ}$ 336, p. 350-35.

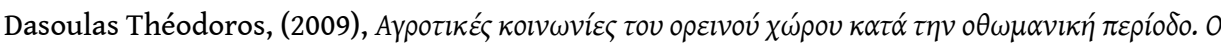

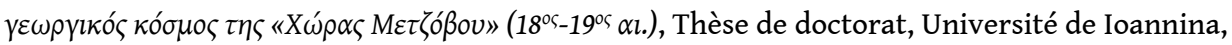
2009, inédite.

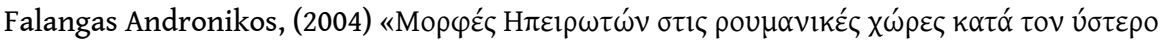

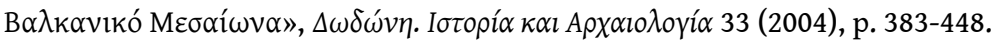

Falangas Andronikos, (2009) Présences grecques dans les Pays roumains (XIV'-XVI siècles). Le témoignage des sources narratives roumaines, Bucarest : Omonia.

Iorga Nicolae, (1911) Studii şi documente cu privire la istoria Românilor, XXI, Documente interne, Bucarest.

Iorga Nicolae, (1903), Studii şi documente cu privire la Istoria Românilor, V, Cărţi domnești, zapise şi răvaşe, Bucarest.

Iorga Nicolae, (1904-5), «Nichifor Dascălul, exarh patriarhal şi legăturile lui cu Ţările noastre», Analele Academiei Române. Memoriile Secţiunii Istorice, II ${ }^{\mathrm{e}}$ série, XXVII (1904-1905), p. 183-200. 
Iorga Nicolae, (1945), «Vasile Lupu ca următor al împăraţilor de răsărit în tutelarea Patriarhiei de Constantinopole şi a Bisericii Ortodoxe», Analele Academiei Române. Memoriile Secţiunii Istorice, II ${ }^{\mathrm{e}}$ série, XXXVI (1913-1914), p. 207-235.

Iorga Nicolae, (1919) «Sfătuitorul bizantin al lui Mihai Viteazul : Mitropolitul Dionisie Rali Paleologul», Revista Istorică V/1-2 (1919), p. 26-35.

Kayapinar Ayşe, (2007), « Les Filorici dans la région timoko-danubienne à l'époque ottomane ( $\mathrm{xv}^{\mathrm{e}}$ $\mathrm{XVI}^{\mathrm{e}}$ siècles) ", dans Enjeux politiques, économiques et militaires en mer Noire (XIVe-XXI ${ }^{e}$ siècles). Études à la mémoire de Mihail Guboglu, Brăila : éd. F. Bilici, I. Câindea, Anca Popescu, p. 243-288.

Kayapinar Ayşe, (2011), Le Sancak ottoman de Vidin du Xve à la fin du XVI siècle, Istanbul.

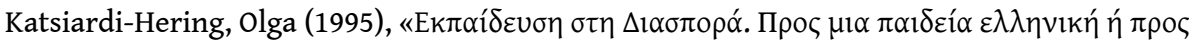

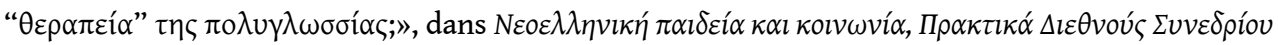

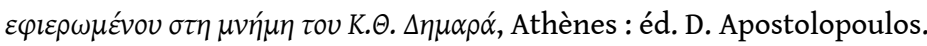

Kravari Vassiliki, (1998), « L'hellénisation des Slaves de Macédoine orientale, au témoignage des anthroponymes », dans Mélanges offerts à Hélène Ahrweiler, II, Paris, p. 387-397.

Kravari Vassiliki, (2005) «Le prénom des paysans en Macédoine orientale ( $\mathrm{X}^{\mathrm{e}-\mathrm{XIV}} \mathrm{X}^{\mathrm{e}}$ siècle) », dans Les villages dans l'Épire byzantine ( $I V^{e}-X V^{e}$ siècle), Paris : éd. J. Lefort, Cécile Morisson, J.-P. Sodini, p. 301-306.

Lazăr Gheorghe, (2006), Les marchands en Valachie, XVII ${ }^{\mathrm{e}}$-XVIII ${ }^{\mathrm{e}}$ siècles, Bucarest : Institut culturel roumain.

Lazăr Gheorghe, (2001), « Documente privitoare la negustorii Pepano şi la ctitoria lor de la Codreni “pe Mostiște” (II) , Studii și materiale de istorie medie XIX (2001), nº 10.

Murgescu Bogdan, (1995) “'Phanariots' and 'Pământeni'. Religion and Ethnicity in Shaping Identities in the Romanian Principalities and the Ottoman Empire", dans Ethnicity and Religion in Central and Eastern Europe, Cluj: éd. Maria Crăciun, O. Chitta, p. 196-204.

Neculce Ion, (1955), Letopiseţul Ţării Moldovei și O samă de cuvinte, Bucarest: éd. I. Iordan.

Pall, François, (1945), « Les relations de Vasile Lupu avec l'Orient orthodoxe et particulièrement avec le Patriarcat de Constantinople, envisagées surtout d'après les lettres de Ligaridis ", Balcania VIII, p. 66-140.

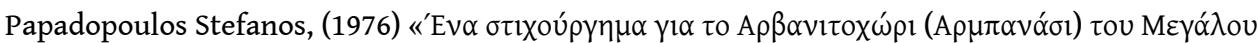

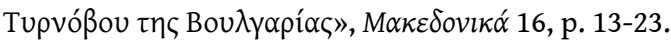

Papahagi Valeriu, (1939) Moscopole metropola comercială şi culturală a românilor din Peninsula Balcanică în secolul al XVIII-lea, Roşiorii-de-Vede.

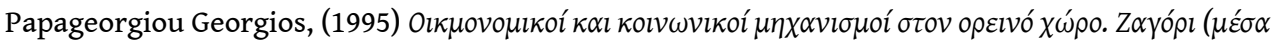
$18^{o v}-\alpha \rho \chi \varepsilon ́ s 19^{\circ v} \alpha$ l.), Ioannina.

Petmezas Sotiris, (1996) « Serrès et sa région sous les Ottomans », dans Conseils et mémoires de Synadinos, prêtre de Serrès en Macédoine (XVII siècle), Paris : éd. P. Odorico.

Pippidi Andrei, (1983-2001) Tradiţia politică bizantină în Ţările române în secolele XVI-XVIII, Bucarest 2001 (1983).

Pippidi Andrei, (1991), «L'histoire de Marcada, ses versions et ses lecteurs », Revue des études sudest européennes XXIX/1-2 (1991), p. 27-37. 
Popescu Anja, (2010) «Străjuirea navigaŢiei pe Dunăre în epoca otomană : derbendcilik-ul , Studii şi materiale de istorie medie XXVIII (2010).

Rakova Snejana (2006), «Traits de la vie commerciale dans les sources diplomatiques et hagiographiques slaves (XIII ${ }^{\mathrm{e}} \mathrm{XVI}{ }^{\mathrm{e}}$ siècles) », Studii şi materiale de istorie medie 24 (2006), p. 17-19.

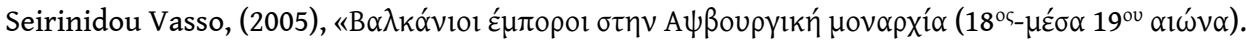

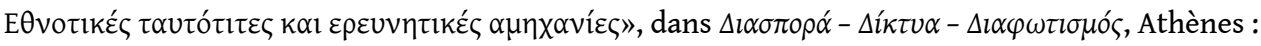
éd. Maria A. Stassinopoulou, Maria Christina Chatziioannou, p. 53-82.

Székely Maria Magdalena, (2006), «Paleologii din Moldova», dans De potestate. Semne şi expresii ale puterii în Evul Mediu românesc, Jassy, p. 525-536.

ştefănescu Stefan, (1960), "Éléments nobiliaires balkaniques établis en Valachie à la fin du XV siècle », Revue roumaine d'Histoire VIII (1960), p. 891-897.

Stoicescu Nicolae, (1971), Dicţionar al marilor dregători din Ţara Românească şi Moldova, sec. XIV-XVII, Bucarest.

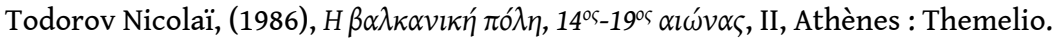

Turdeanu Emil, (1939), «Din vechile schimburi culturale dintre români şi jugoslavi , Cercetări literare III (1939), p. 141-218.

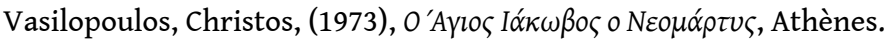

Vătăşescu Cătălina, (2005), « De nouveau sur l'emploi en roumain de l'ethnonyme sârbi « Serbes » pour désigner les Bulgares aussi », tiré à part de Linguistique balkanique. In memoriam Maxim Mladenov XLIV/1-2 (2005), p. 142-152.

Yerasimos Stefanos, (2005), « Les Grecs d'Istanbul après la Conquête de Constantinople », Revue du Monde musulman et de la Méditerranée 107-110.

\section{NOTES}

1. M. Cazacu, «La chancellerie des Principautés valaque et moldave (XIV ${ }^{\mathrm{e}} \mathrm{XVIII}$ e siècles) ", dans Kanzleiwesen und Kanzleisprachen im östlichen Europa, éd. Chr. Hannick, Vienne, 1999, p. 87-127, avec la bibliographie du sujet.

2. Par exemple, vers 1674-1678, Lamba (Lambru) cămăraş de Ocnele-Mari a fondé, d'un commun effort avec Dionisie «grecul» (le Grec) de Ioannina, l'église de Ţeica, en Valachie : I. PopescuCilieni, Biserici, târguri şi sate din jud. Vâlcea, Craiova 1941, p. 71, n. 2. Lamba cămăraş ne pouvait être qu'un compatriote de l'autre ktitor, Dionisie de Ioannina. D'ailleurs, son nom personnel, Lambru (du grec Lambros), était caractéristique des Épirotes de la région de Ioannina et des environs. Voir aussi le cas des marchands Babula (Babulaio), Alfangi et Sugdureşti (Surid) de Bucarest (fin du XVII ${ }^{\mathrm{e}}$ siècle), mentionnés aux côtés de Bălan Ironimul. On sait que Bălan Ironimul (Balanos Hiéromnimon) était originaire de Ioannina et qu'il avait pour proches parents les Babulaios, les Alfantzis et les Sougdouris de la même ville que lui : pour tous, voir Lidia Cotovanu, «Chi "finanziò" gli studi a Padova di siniscalco Costantino Cantacuzeno (1667-1669)?», dans La storia di un ri-conoscimento: i rapporti tra l'Europa Centro-Orientale e la Panisola italiana dal Renascimento all'Età dei Lumi, éd. Cr. Luca et G. Masi, Brăila-Udine 2012, p. 291-328. On tiendra donc les marchands Babula, Alfangi et Sugdureşti de Bucarest comme étant tous originaires de Ioannina. Pour les marchands et douaniers Condarat de Moldavie, il est difficile d'établir les liens de parenté exacts qui les unissaient. Mais le fait qu'ils soient tous attachés à la gestion des douanes moldaves laisse entendre qu'ils étaient des proches parents. On sait que l'un d'entre eux 
était l'oncle du patriarche de Constantinople Parthenos II, un Épirote : C.A. Stoide, «Din legăturile Patriarhiei de Constantinopol cu Moldova în epoca lui Vasile Lupu», Mitropolia Moldovei şi a Sucevei xxxIv/7-8 (1958), p. 564-569. On retrouve, effectivement, les noms de certains Condarat, en leur qualité de ktitors, au monastère de Sosinou de Pogdoriani, dans le diocèse épirote de Vella et Konitsa, monastère refait au début $d u x_{\text {XII }}$ siècle par le marchand et grand douanier de

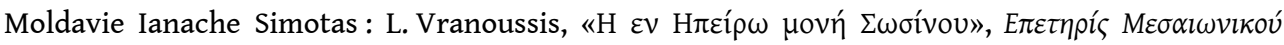
Apxcíov 4 (1957), p. 72-129. Cela permet de considérer les Condarat de Moldavie comme étant originaires du diocèse de Vella et Konitsa, là où est situé le monastère de Sosinou. Les exemples pourraient être encore multipliés.

3. Les individus qui portent le surnom de «Brousiotis» (il s'agit d'un certain Zotos) ou «Halepli », indiquant leur lien avec les villes de Brousse ou d'Alep, pourraient n'être en fait que des marchands balkaniques qui vendaient leurs marchandises dans les villes en question ou qui s'approvisionnaient en produits orientaux là bas : voir N. Todorov, $H \beta \alpha \lambda \kappa \alpha v i \kappa \eta ́ n ~ \pi o ́ \lambda \eta, 14^{\circ \varsigma}-19^{\circ} \varsigma$ $\alpha \iota \omega ́ v \alpha \varsigma$, II, Athènes 1986, p. 302 ; Gh. Lazăr, Les marchands en Valachie, XVII ${ }^{e}$-XVIII ${ }^{e}$ siècles, Bucarest 2006, p. 278 et n. 173.

4. Pour l'immigration sud-slave en Valachie, «serbe " notamment, voir tout particulièrement E. Turdeanu, «Din vechile schimburi culturale dintre români şi jugoslavi», Cercetări literare III (1939), p. 141-218; şt. ştefãnescu, « Élément nobiliaires balkaniques établis en Valachie à la fin du $\mathrm{XV}^{\mathrm{e}}$ siècle", Revue roumaine d'Histoire VIII (1960), p. 891-897; D. Mioc, «Date noi cu privire la Macarie Tipograful», Studii. Revista de istorie XVI/2 (1963), p. 429-440 ; I.-R. Mircea, «Relations culturelles roumano-serbes au $\mathrm{XVI}^{\mathrm{e}}$ siècle », Revue des études sud-est européennes I/3-4 (1963), p. 377-419 ; A. Pippidi, Traditiia politică bizantină în Ţările române în secolele XVI-XVIII, Bucarest 2001 (1983), p. 79-80.

5. D'autres chercheurs ont déjà remarqué la présence "grecque » majoritairement épirote dans les Principautés de Valachie et de Moldavie des $\mathrm{XVI}^{\mathrm{e}}{ }^{\mathrm{e}} \mathrm{XVII}{ }^{\mathrm{e}}$ siècles: Ariadna Camariano-Cioran,

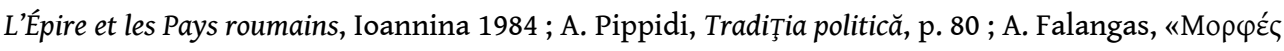

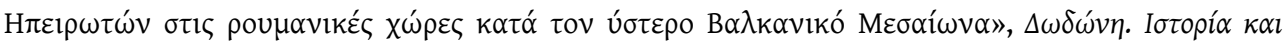

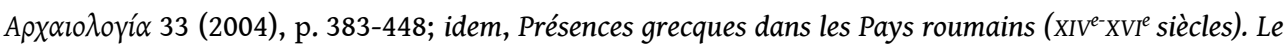
témoignage des sources narratives roumaines, Bucarest, 2009, p. 223-240.

6. Gh. Lazăr,«Documente privitoare la negustorii Pepano şi la ctitoria lor de la Codreni "pe Mostişte" (II)», Studii şi materiale de istorie medie XIX (2001), nº 10, p. 266-267.

7. C'est le cas, par exemple, des « arbănaşi » de Călineşti (dépt. de Prahova, en Valachie), colons arrivés de Cernavoda (aujourd'hui en Bulgarie): Violeta Barbu, «Les Arbanassi: un réseau marchand aux frontières de l'Empire ottoman au début du XVII ${ }^{\mathrm{e}}$ siècle », Études balkaniques XLVI/ 1-2 (Sofia 2010), p. 206-222.

8. Fr. Babinger, "Originea şi sfârşitul lui Vasile Lupu», Analele Academiei Române. Memoriile Secţiunii Istorice, III ${ }^{\mathrm{e}}$ série, XVIII (1936), p. 63-73 ; idem, "Originea lui Vasile Lupu», Analele Academiei Române. Memoriile Secţiunii Istorice, III ${ }^{\mathrm{e}}$ série, XIX (1937), p. 137-143; L. Cotovanu, « Le diocèse de Dryinoupolis et ses bienfaiteurs de Valachie et de Moldavie. Solidarités de famille et traits identitaires multiples (XVI ${ }^{\mathrm{e}}-\mathrm{XVII}{ }^{\mathrm{e}}$ siècles) », dans ContribuŢii privitoare la istoria relaţiilor dintre Ţările Române și Bisericile Răsăritene în secolele XIV-XIX, éd. P. Zahariuc, Jassy 2009, p. 240-257.

9. T. Papahagi, Moscopole metropola comercială şi culturală a românilor din Peninsula Balcanică în

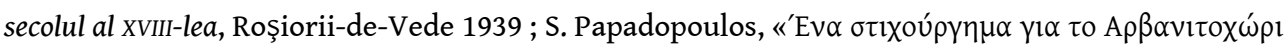

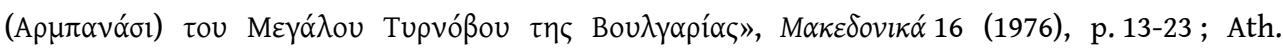
E. Karathanassis, "Yannakis Adami : un lettré de la deuxième moitié du dix-huitième siècle, originaire d'Albanitohori ", dans Cultural Relations between Greek and Bulgarians from the Middle of the 15th to the Middle of the 19th C.I Greek-Bulgarian Symposium organized in Thessaloniki (22-25 September 1978) by the "Institute for Balkan Studies" in Thessaloniki and the "Institut za 
Balkanistika Pri Ban" in Sofia, Thessalonique 1980, pp. 177-179; Olga Cicanci, Companiile grecești

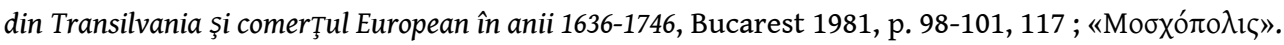

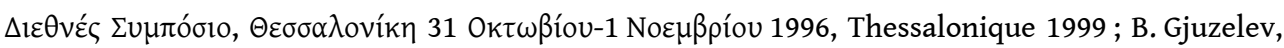
Albantsi v Izmotchnime Balkani, Sofia 2004, p.50-57, 88-90; A. Falangas, Présences grecques, p. 238-239, 272.

10. Remarque de A. Falangas, op. cit., p. 272.

11. şt. Ciobanu, «Informations sur la Valachie au $\mathrm{XVI}^{\mathrm{e}}$ siècle dans une œuvre hagiographique bulgare », Balcania VII/1 (1944), p. 121-151; Snejana Rakova, " Traits de la vie commerciale dans les sources diplomatiques et hagiographiques slaves ( $\mathrm{XIII}^{\mathrm{e}}-\mathrm{XVI}^{\mathrm{e}}$ siècles) », Studii şi materiale de istorie medie 24 (2006), p. 17-19.

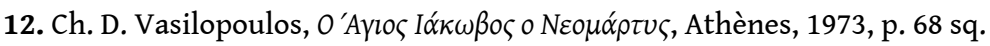

13. A. Tertecel, «O problemă de geografie istorică. Cernavoda şi Cervena Voda», Studii şi materiale de istorie medie Xx (2002), p. 343-346; Violeta Barbu, « Les Arbanassi », art. cit., p. 206-222.

14. Archives d'État de Bucarest, Mănăstirea Plumbuita, XII/4 (1641, <sept. 10>), résumé dans Catalogul documentelor Țării Româneşti din Arhivele Statului, V (1640-1644), éd. M.-D. Ciucă, Doina Duca-Tinculescu, Silvia Vătafu-Găitan, Bucarest 1985, nº 496, p. 231 ; N. Stoicescu, Dicţionar al marilor dregători din Ţara Românească şi Moldova, sec. XIV - XVII, Bucarest 1971, p. 195-196 ; Gh. Lazăr, Les marchands, op. cit., p. 264-265 ; şt. Aftodor, “The land estate of boyar Hrizea from Bălteni”, Istros XVII (2011), pp. 235-257.

15. L. Cotovanu, « Le diocèse de Dryinoupolis ", art. cit., p. 262-275.

16. Documente privitoare la istoria oraşului Iaşi, I, Acte interne (1408-1660), éd. I. Caproşu, P. Zahariuc, Jassy $1999, n^{\circ} 364$, p. 433 ; supra, n. 3. On apportera à l'appui de cette constatation le cas de

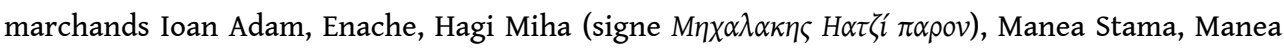
Nikolaou (signe $M \alpha v \omega \varsigma N \eta \kappa \omega \lambda \alpha o v \mu \alpha \rho \tau \eta \rho \alpha \varsigma$ ), Nica, Rustea - originaires d'Épire et des environs, à en juger d'après leurs noms -, qui sont connus des sources moldaves comme étant de la ville de Sharhorod (aujourd'hui en Ukraine), suite aux activités commerciales qu'ils déployaient là-bas : C.A. Stoide, «Negustorii din şarhorod în Moldova», Revista Istorică Română V-VI (1935-1936), p. 382-387.

17. Archives d'État de Bucarest, Documente istorice, cccLxxIX/1 (1710, mai 17) ; I. Popescu-Cilieni, Biserici, târguri şi sate din jud. Vâlcea, op. cit., p. 72, n. 3 ; G. Potra, Documente privitoare la istoria oraşului Bucureşti (1634-1800), Bucarest 1982, $n^{\circ}$ 49, p. 93, nº 98, p. 137 ; idem, Documente privitoare la istoria oraşului Bucureşti (1594-1821), Bucarest 1961, nº 108, p. 192-193.

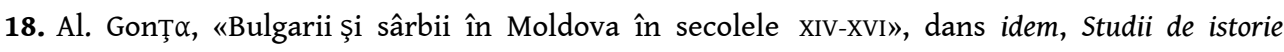
medievală, éd. șt.S. Gorovei, Maria-Magdalena Székely, Jassy 1998, p. 73-88 ; Cătălina Vătăşescu, "De nouveau sur l'emploi en roumain de l'ethnonyme sârbi "Serbes" pour désigner les Bulgares aussi ", tiré à part de Linguistique balkanique. In memoriam Maxim Mladenov XLIV/1-2 (2005), p. $142-152$.

19. J'ai comparé ces noms avec ceux des nombreux habitants des régions sud-slaves enregistrés par les registres de recensement ottomans de la seconde moitié du $\mathrm{xv}^{\mathrm{e}}$ et $\mathrm{du} \mathrm{xvI}^{\mathrm{e}}$ siècle. Effectivement, une grande partie de ces noms y sont d'usage très fréquent (il serait long de citer ici tous les cas que j'ai pu recenser) : voir, par exemple, Turski izvori za balgarscata istorija. Serija XVXVI, II, éd. N. Todorov, B. Nedkov, Sofia 1966 ; Turski dokumenti za istorijata na makedonskiot narod. Opshiren popisen Defter N 4 (1467-1468 godina), éd. M. Sokoloski, Al. Stojanovski, Skopje 1971 ; Turski dokumenti za istorijata na makedonskiot narod. Opshiren popisen Defter od XV vek, II, éd. M. Sokoloski, Skopje 1973 ; Turski dokumenti za istorijata na makedonskiot narod. Opshiren popisen Defter od XV vek, III, éd. M. Sokoloski, Skopje 1976; Turski dokumenti za istorijata na makedonskiot narod. Opshiren popisen Defter od XV vek, IV, éd. M. Sokoloski, Skopje, 1978. Le répertoire des noms communs aux espaces des deux rives du Danube est très vaste. J'ai choisi ici uniquement ceux qu'on rencontre 
très rarement dans les Principautés, ce qui peut indiquer, en effet, qu'on a affaire à des immigrés ou des descendants d'immigrés.

20. Le préjugé s'est instauré dans l'historiographie roumaine que l'immigration sud-slave diminue au cours de la première moitié $d u x V I^{e}$ siècle, pour laisser la place à l'immigration « grecque » qui n'a cessé d'augmenter tout au long des XVII ${ }^{\mathrm{e}}$-XVIII ${ }^{\mathrm{e}}$ siècles.

21. Maints autres Paléologues s'étaient installés dans les Principautés et au moins une partie d'entre eux devaient être originaires de Constantinople : Cr.N. Apetrei, «Un urmaş al împăraţilor bizantini, negustor, dregător şi diplomat în slujba Movileştilor: marele postelnic Dumitrache Chiriţă Paleologul», dans Negustorimea în Ţările Române, între Societas Mercatorum şi individualitatea mercantilă, în secolele XVI-XVIII, éd. Cr. Luca, GalaŢi 2009, p. 89-125 ; Maria Magdalena Székely, «Paleologii din Moldova», dans De potestate. Semne și expresii ale puterii în Evul Mediu românesc, Jassy 2006, p. 525-536.

22. Fait remarqué déjà par P.ş. Năsturel, « Témoignages roumains sur des Épirotes de Konitsa,

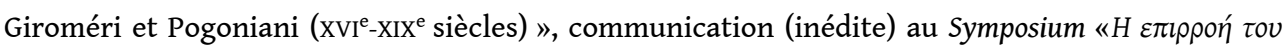

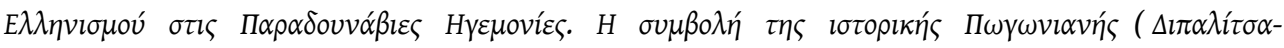

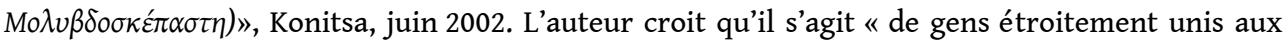
cercles du Patriarcat ». Il faut y ajouter, sans doute, les activités commerciales et la recherche d'autres types d'emplois qui les amenaient à Istanbul.

23. Catalogul documentelor Ţării Românești din Arhivele NaŢionale, VIII (1654-1656), éd. M.-D. Ciucă, Silvia Vătafu-Găitan, D. şesan, Mirela Comănescu, Bucarest 2006, n 809, p. 367 (1656, fév. 10) ; Ion Neculce, LetopiseŢul Ţării Moldovei şi O samă de cuvinte, éd. I. Iordan, Bucarest 1955, chap. XXXVII, p. 118-119; P. Cernovodeanu, «ştiri privitoare la Gheorghe Ghica Vodă al Moldovei (1658-1659) şi la familia sa (I)», Anuarul Institutului de Istorie şi Arheologie «A.D. Xenopol», Jassy XIX (1982), p. 332-352, p. 333.

24. N. Iorga, Studii şi documente cu privire la istoria Românilor, XXI, Documente interne, Bucarest 1911, p. 95-100 ; A. Pippidi, «L'histoire de Marcada, ses versions et ses lecteurs », Revue des études sudest européennes XXIX/1-2 (1991), p. 27-37.

25. N. Iorga, Studii şi documente cu privire la Istoria Românilor, V, CărŢi domnești, zapise şi răvaşe, Bucarest 1903, p. 309 ; Crina-Mihaela Rafailă, Documentele epocii brâncovenești în colecţiile Muzeului Municipiului Bucureşti, Bucarest 2008, n 336, p. 350-351 ; P. Cernovodeanu, «Un "Homo novus" la curtea lu Brâncoveanu: Vergo marele clucer şi familia sa», Arhiva Genealogică VI (xI)/ 1-4 (1999), p. 117-130. À remarquer tout de même qu'au XVII ${ }^{\mathrm{e}}$ siècle, il devait y avoir encore aux alentours de Constantinople des villages peuplés par les descendants des plus de 7000 Serbes, Bosniaques et Épirotes ou encore des 10000 Grecs et Albanais de Péloponnèse, qui y avaient été installés après la conquête ottomane de la ville: St. Yerasimos, «Les Grecs d'Istanbul après la Conquête de Constantinople ", Revue du Monde musulman et de la Méditerranée 107-110 (2005), p. 379, 381, 383-384, 391-393.

26. A. Falangas, Présences grecques, p. 216.

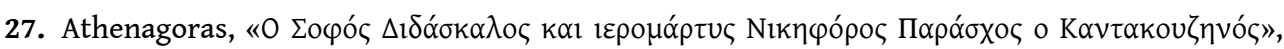

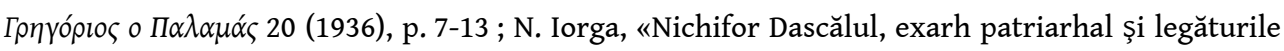
lui cu Ţările noastre», Analele Academiei Române. Memoriile Secţiunii Istorice, II ${ }^{\mathrm{e}}$ série, XXVII (1904-1905), p.183-200 ; P.P. Panaitescu, «Despre Nichifor Dascălul şi legăturile lui cu noi», Revista istorică XII/4-6 (1926), p. 83 ; șt. Andreescu, «Exarhul patriarhal Nichifor Dascălul, cneazul Constantin Vasile de Ostrog şi Mihai Viteazul», dans idem, Restitutio Daciae, III, Studii cu privire la Mihai Viteazul, Bucarest 1997, p. 81-113.

28. I. Dujčev, «Démétrius Cantacuzène écrivain byzantino-slave du $\mathrm{xv}^{\mathrm{e}}$ siècle», Medioevo bizantinoslavo, III, Rome 1971, p. 311-321 ; A.-E. Tachiaos, « Nouvelles considérations sur l'œuvre littéraire de Démétrius Cantacuzène », Cyrillomethodianum I (1971), p.131-152; M. Cazacu, «Stratégies 
matrimoniales et politiques des Cantacuzène de la Turcocratie ( $\mathrm{xv}^{\mathrm{e}}-\mathrm{XVI}^{\mathrm{e}}$ siècles) », Revue des études roumaines XIX-XX (1995-1996), p. 157-181; I. Cantacuzino, M. Cazacu, «Généalogie et empire. Les Cantacuzène de l'époque byzantine à l'époque ottomane ", dans L'empereur hagiographe. Culte des saints et monarchie byzantine et post-byzantine, éd. P. Guran, B. Flusin, Bucarest 2001, p. 294-308.

29. N. Iorga, «Sfătuitorul bizantin al lui Mihai Viteazul: Mitropolitul Dionisie Rali Paleologul», Revista Istorică V/1-2 (1919), p. 26-35; D. Dima, «Mitropolitul Dionisie Rally Paleologul şi legăturile lui cu Biserica şi Ţările române», Biserica Ortodoxă Română LXXXIII/5-6 (1965), p. 521-532 ; A. Pippidi, Tradiţia politică, op. cit., p. 266-272, 287-289 ; M. Cazacu, "Stratégies matrimoniales », art. cit., p. 176 ; idem, «Despre câteva vechi biserici bucureştene din veacurile XVI-XVIII», dans Aut viam inveniam aut faciam. In honorem ştefan Andreescu, éd. O. Cristea, P. Zahariuc, Gh. Lazăr, Jassy 2012, Jassy, p. 469-492.

30. J'ai comparé ces noms avec un vaste répertoire anthroponymique que j'ai pu établir sur la base des sources grecques, publiées, émises dans les régions balkaniques ou en rapport avec elles (actes ecclésiastiques, testaments, actes de donation, inscriptions votives, obituaires, etc.). Il serait long de citer ici le répertoire en question et toute la bibliographie consultée.

31. Remarquons que le nom Caraman désigne quelqu'un au teint foncé et non l'individu originaire

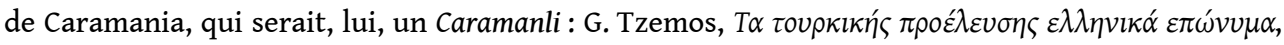
Thessalonique 2003, p. 107. Il y a dans les Principautés, effectivement, des Caraman (Caraiman) et des Caramanlâu : G. Franck, «Grecii din Moldova - între integrare şi asimilare (sfârşitul secolului XVI - prima jumătate a secolului XVII). Modele de ascensiune socială», dans Etnie şi confesiune Moldova medievală, éd. I. Toderaşcu, Jassy 2006, p. 215-230 ; N. Stoicescu, Dicţionar, op. cit., p. 146. Quant aux immigrés appelés du nom de Caragea, ils devaient être originaires plutôt de quelque part des régions balkaniques de langue grecque que de l'île de Chios ou d'Asie Mineure ; j'en apporterai la démonstration à une autre occasion. Voir tout de même C.I. Karadja, «Sur l'origine des Karadja ", Revue historique des études sud-est européennes xv/7-9 (1938), p. 225.

32. L'apparition précoce des noms turcs dans les sources valaques et moldaves est le signe, d'une part, des réminiscences coumanes et tatares dans l'espace carpatho-danubien (Aga, Basarab, Berindei, Toxabă etc.) et, d'autre part, de la conquête turco-ottomane des régions balkaniques dès la fin du XIve siècle et des conversions des Chrétiens des lieux à l'Islam. Les registres de recensement ottomans, datant de la seconde moitié $d u x^{e}$ siècle, témoignent déjà d'un nombre important de renégats : voir les sources citées à la note 19, supra.

33. Or, il n'est pas rare de trouver des noms slaves (bulgares et/ou serbes) dans la Macédoine orientale, en Épire et en Thessalie, réminiscences de l'installation des anciens Slaves dans ces régions ( $\mathrm{VII}{ }^{\mathrm{e}}$ siècle) et des conquêtes bulgares et serbes (XIII ${ }^{\mathrm{e}}$ et $\mathrm{XIV}^{\mathrm{e}}$ siècles) ou d'autres migrations occasionnelles : voir, par exemple, Vassiliki Kravari, «L'hellénisation des Slaves de Macédoine orientale, au témoignage des anthroponymes », dans Mélanges offerts à Hélène Ahrweiler, II, Paris 1998, p. 387-397 ; eadem, "Le prénom des paysans en Macédoine orientale ( $\mathrm{x}^{\mathrm{e}}$-XIV ${ }^{\mathrm{e}}$ siècle) ", dans Les villages dans l'Epire byzantine ( $I V^{e}-X V^{e}$ siècle), éd. J. Lefort, Cécile Morisson, J.-P. Sodini, Paris <2005>, p. 301-306. Les noms slaves se sont retrouvés aussi dans l'île d'Eubée, apportés par les immigrés épirotes, mentionnés comme étant des « Albanais »: Evangelia Balta, L’Eubée à la fin du XV $V^{e}$ siècle. Économie et population. Les registres de l'année 1474, Athènes 1989, passim.

34. Pour le porteurs des noms Dima, Iane, Ianache, Manu (Manea), Miha (Mihu) et Sima, noms de diffusion plus vaste dans les Balkans et dans les Principautés, je n'ai retenu que ceux qui apposent leur signature en grec et/ou ceux qui sont désignés comme étant des «Grecs » ou encore ceux dont les enfants et les petits-enfants portent des noms caractéristiques des espaces balkaniques de langue grecque.

35. Les premiers signes de présence épirote en Valachie, très modestes encore, datent de la fin même du XIV $\mathrm{XV}^{\mathrm{e}}$ siècle, mais elle prend de l'essor à partir de la fin $\mathrm{du} \mathrm{XV}^{\mathrm{e}}$ siècle et augmente tout au long du siècle suivant. 
36. Les résultats de mon enquête concordent avec les constatations de Olga Katsiardi-Hering,

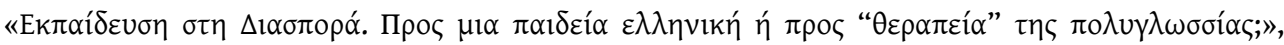

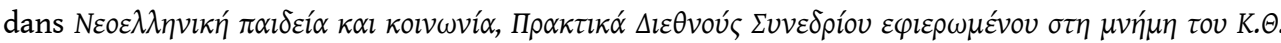
$\Delta \eta \mu \alpha \rho \alpha$, éd. D. Apostolopoulos, Athènes 1995, p. 155, qui observe la répartition suivante de l'émigration des sujets chrétiens des sultans ( $\left(\mathrm{u} \mathrm{XVIII}^{\mathrm{e}}\right.$ et du début $\mathrm{du} \mathrm{XIX}^{\mathrm{e}}$ siècle), pour des raisons commerciales : les originaires des îles et des bords des mers Égéenne et Ionienne ont pris le chemin des villes italiennes et de celles du sud de la Russie, alors que ceux originaires de Macédoine, d'Épire, de Thessalie, du Sud de l'ancienne Serbie et de Bulgarie ont opté pour l'Empire des Habsbourg et notamment pour l'Autriche, la Croatie, les régions frontalières, peuplées par des Serbes et des Valaques, la Hongrie et la Transylvanie, celles-ci se trouvant dans le voisinage immédiat de la Valachie et de la Moldavie. On conclura que l'orientation de cette dernière catégorie de migrants vers l'Europe centrale ne fit que continuer une tradition plus ancienne qui, durant les trois siècles antérieurs, s'était concentrée en Valachie, en Moldavie et

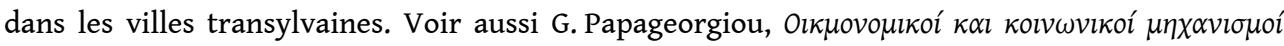

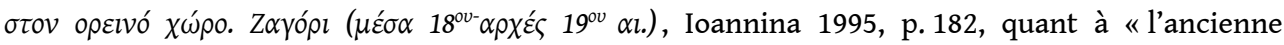
tradition d'émigration » des habitants du Zagori épirote vers les Principautés danubiennes, ainsi que les études réunies par Maria A. Stassinopoulou, Maria Christina Chatziioannou (éd.), $\Delta \iota \alpha \sigma \pi o \rho \alpha ́$ - $\Delta i ́ k \tau v \alpha$ - $\Delta \imath \alpha \varphi o \tau \imath \sigma \mu o ́ \varsigma$, Athènes 2005, qui soulignent la forte présence des Valaques balkaniques (de Macédoine et d'Épire notamment) dans les échanges commerciaux entre l'Empire ottoman et le Royaume de Hongrie ou l'Empire des Habsbourg (voir surtout p. 25, 67-81).

37. L'attachement tout particulier des couples princiers aux lieux de culte de l'espace constantinopolitain et sud-slave reflète non seulement leur engagement dans l'œuvre de patronage de l'Église orthodoxe tout entière, dictée par les attributions liées à l'exercice de leur pouvoir autocratique et par leur désir d'imiter les têtes couronnées qui les avaient précédés, mais aussi leur appartenance à des réseaux de parentés qui s'étendaient jusque dans la capitale de l'Empire (byzantin puis ottoman) et les îles égéennes. Très souvent, les princes ne faisaient que confirmer les actes de donation de leurs prédécesseurs couronnés, ce qui leur valait quand même la qualité de nouveaux ktitors des édifices secourus : P.ş. Năsturel, Le Mont Athos et les Roumains. Recherches sur leurs relations du milieu du XIve siècle à 1654, Rome 1986, passim.

38. L. Cotovanu, " "Qu'on prie pour moi là-bas et ici”. Donation religieuse et patriotisme local dans le monde orthodoxe des $\mathrm{xVI}^{\mathrm{e}}$-XVII ${ }^{\mathrm{e}}$ siècles", communication dans le cadre du colloque "Histoire, mémoire et dévotion. Regards croisés sur la construction des identités à l'Est (Moyen Age, Temps modernes). History, memory and devotion. Comparative perspectives on identities in Eastern Europe (Middle Ages, Modern Times) », 13-14 novembre 2009, École des Hautes Études en Sciences sociales, Paris, en cours de publication.

39. N. Beldiceanu, Irène Beldiceanu-Steinherr, "Quatre actes de Mehmed II concernant les Valaques des Balkans slaves", Südost-Forschungen xxIV (1955), p. 103-118; N. Beldiceanu, «La région de Timok-Morava dans les documents de Mehmed II et de Selim I ", Revue des études roumaines III-IV (1957), p. 111-129; idem, « Sur les Valaques des Balkans slaves à l'époque ottomane (1450-1551)», Revue des études islamiques 4 (1966), p. 83-132; idem, "Les Valaques de Bosnie à la fin du XV siècle et leurs institutions ", Turcica VII (1975), p. 122-134; idem, "Populations chrétiennes et franchises dans l'Empire ottoman", dans Lo Stato e il potere nel Rinascimento, Mélanges Federico Chabod, Perugia 1981, p. 101-111; idem, «Les Roumains des Balkans dans les sources ottomanes ", Études roumaines et aroumaines (1990), p. 11-19; M. Berindei, Annie Berthier, Marielle Martin, G. Veinstein, « Code de lois de Murad III concernant la province de Smederevo », Südost-Forschungen XXXI (1972), p. 146-147, $\mathrm{n}^{\circ} \mathrm{VI}$, p. 153-154, $\mathrm{n}^{\circ}$ VIII, p. $154, \mathrm{n}^{\circ} \mathrm{XI}$, p. 160 ; N. Beldiceanu, I. Beldiceanu-Steinherr, P.ş. Năsturel, «Les recensements ottomans effectués en 1477,1519 et 1533 dans les provinces de Zvornik et d'Herzégovine », Turcica XX (1988), p. 160,

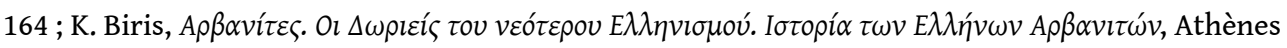


$1998^{4}$, p. 214-218 ; A. Rigo, «Lo horismòs di Sinân Pascià, la presa di Ioannina (1430) e la "lettera"

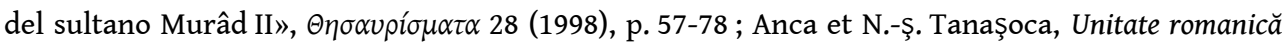
şi diversitate balcanică. ContribuŢii la istoria romanităŢii balcanice, Bucarest 2004 ; Ayşe Kayapinar, «Les Filorici dans la région timoko-danubienne à l'époque ottomane ( $\mathrm{xv}^{\mathrm{e}}-\mathrm{XVI}^{\mathrm{e}}$ siècles) », dans Enjeux politiques, économiques et militaires en mer Noire (XIVe-XXI ${ }^{e}$ siècles). Études à la mémoire de Mihail Guboglu, éd. F. Bilici, I. Câindea, Anca Popescu, Brăila 2007, p. 243-288 ; eadem, Le Sancak ottoman

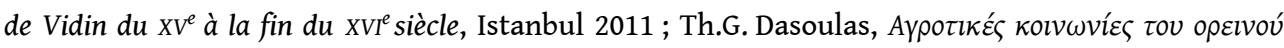

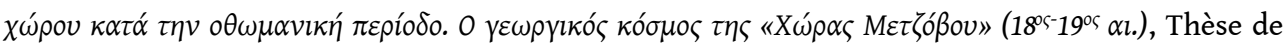
doctorat, Université de Ioannina, 2009, inédite, p. 127-148; Anca Popescu, «Străjuirea navigaŢiei pe Dunăre în epoca otomană: derbendcilik-ul», Studii şi materiale de istorie medie XXVIII (2010), p. 149-168, etc.

40. Voir les considérations de S. Petmezas, "Serrès et sa région sous les Ottomans ", dans Conseils et mémoires de Synadinos, prêtre de Serrès en Macédoine (XVII siècle), éd. P. Odorico, Paris 1996, p. 480, à propos des quartiers paroissiaux des villes chrétiennes bénéficiaires du droit de charité, en raison de leur soumission volontaire au conquérant ottoman : «Les quartiers disposaient d'un droit de contrôle sur les déplacements de leurs habitants. Tous les membres de chaque corps collectif étaient soudés par des liens de solidarité et des contraintes collectives ».

41. Effectivement, les immigrés balkaniques des Principautés étaient le plus souvent des célibataires, fait remarqué aussi par I.D. Condurachi, Câteva cuvinte asupra condiţiei juridice a străinilor în Moldova şi Ţara Românească până la Regulamentul Organic, Bucarest 1918, p. 62.

42. Voir Ayșe Kayapinar, «Les Filorici dans la région timoko-danubienne », art. cit., qui a étudié le statut privilégié des 492 villages valaques de la province ottomane de Vidin, statut supprimé en douceur vers 1560, ce qui a provoqué la désertion d'une partie des villages (p. 256-257). Il serait intéressant de savoir où s'étaient réfugiés tant de Valaques, habitués au maniement des armes et à la garde des frontières, des routes et d'autres points stratégiques.

43. Voir encore les considérations de S. Petmezas, "Serrès et sa région sous les Ottomans ", art. cit., p. 446, au sujet de la solidité et de l'imperméabilité des réseaux marchands balkaniques: «Les réseaux commerciaux locaux interdisaient à tout étranger l'accès direct aux lieux de production et avaient ainsi réussi pendant longtemps à capter une grande partie du surplus agricole. C'est grâce à ces marchands que la production locale fut concentrée, commercialisée et exportée hors de l'Empire ». Certes, les réseaux marchands balkaniques s'étaient étendus, depuis le $\mathrm{xv}^{\mathrm{e}}$ siècle, jusque dans les Principautés danubiennes, où ils s'étaient assuré le monopole de la commercialisation et de l'exportation des matières premières locales: voir, dernièrement, Gh. Lazăr, Les marchands, op. cit. ; L. Cotovanu, «Chi "finanziò" gli studi a Padova», art. cit. ; Cr. Luca, "The Rise of the Greek 'Conquering Merchant' in the Trade between the Eastern Mediterranean and the Romanian Principalities in the Sixteenth and Seventeenth Centuries", Journal of Mediterranean Studies XIX/2 (2010), pp. 314-317; Cr.N. Apetrei, «Marele negustor grec din Moldova (cca 1570-1620). Un profil colectiv din perspectivă braudeliană», Revista istorică XXIII/1-2 (2012), p. 65-84, où le lecteur trouvera la vaste bibliographie du sujet.

44. Supra, n. 39.

45. G. Potra, Documente, op. cit., Bucarest, 1961, $\mathrm{n}^{\circ} 36$, p.115-116 (1657, avril 16). Les "Coutsovalaques" des contrées grecques étaient bien connus du grand sénéchal de Valachie Constantin Cantacuzène (fin du XVII ${ }^{\mathrm{e}}$ siècle) et du prince Dimitrie Cantemir de Moldavie (début du XVIII ${ }^{\mathrm{e}}$ siècle) : Istoria Ţării Românești atribuită stolnicului Constantin Cantacuzino, éd. Otilia Dragomir, Bucarest 2006, p.176-177 et n.316; D. Cantemir, Descriptio Moldaviae - Descrierea Moldovei, traduction roumaine de Gh. GuŢu, Bucarest 1973, p. 366 (texte latin), p. 367 (trad. roum.).

46. Voir, entre autres, A. Armbruster, La romanité des Roumains. Histoire d'une idée, Bucarest 1977, p. 17-22 ; les études réunies dans Centre d'études des civilisations de l'Europe Centrale et du SudEst. Cahier nº 8, Les Aroumains (INALCO 1989); St. Brezeanu, Romanitatea orientală în Evul Mediu, 
Timişoara 1999, p. 101-105, 156 et passim ; P.P. Panaitescu, Introducere la istoria culturii românești. Problemele istoriografiei române, éd. D.H. Mazilu, Bucarest, 2000 (1969), p. 127-130 ; ş. Papacostea, Limbă şi identitate etnică în evul mediu românesc, Bucarest 2001, p. 5-7.

47. Voir les exemples cités par A. Falangas, Présences grecques, op. cit., p. 287-294.

48. Pour les révoltes au caractère "anti-grec» des Principautés, voir tout particulièrement E. Stănescu, "Préphanariotes et Phanariotes dans la vision de la société roumaine des XVII $\mathrm{XVIII}^{\mathrm{e}}$ siècles ", dans Symposium "L'époque phanariote», 21-25 octobre 1970. À la mémoire de Cléobule Tsourkas, Thessalonique 1974, p.347-358; C. Rezachevici, «Fenomene de criză social-politică în Ţara Românească în veacul al xvII-lea. Partea I : Prima jumătate a secolului al XVII-lea», Studii şi materiale de istorie medie Ix (1978), p. 58-84; idem, «Fenomene de criză social-politică în ţara Românească în veacul al XVII-lea. Partea a II-a : A doua jumătate a secolului al XVII-lea», Studii şi materiale de istorie medie XIV (1996), p. 85-117. Pour les hauts dignitaires mentionnés, voir N. Stoicescu, Dicţionar, op. cit., p. 202-203, 219, 299-300, 377-378; M. Cazacu, « Niko de Frastani ou Nica de Corcova : un Epirote au service des princes de Valachie (c. 1560-1618) », Studii şi materiale de istorie medie XXVI (2008), p. 197-210.

49. Comparer avec le cas des Valaques originaires d'espaces de langue grecque, installés dans l'Empire des Habsbourg au XVIII ${ }^{\mathrm{e}}$-milieu du XIX ${ }^{\mathrm{e}}$ siècle, qui partageaient des appartenances collectives multiples et qui avaient la liberté d'afficher la plus convenable, en fonction des

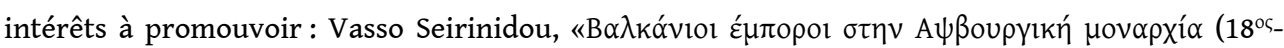

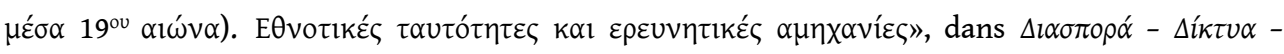
$\Delta \iota \alpha \varphi \omega \tau \imath \sigma \mu o ́ s$, éd. Maria A. Stassinopoulou, Maria Christina Chatziioannou, Athènes 2005, p. 53-82 50. Tout comme le prince Matei Basarab (1632-1654) le fit en Valachie, Vasile Lupu s'empara du trône moldave en s'attaquant au prince nommé par la Porte, Alexandru Iliaş, connu pour s'être entouré d'une nombreuse clientèle "grecque» amenée d'Istanbul: M. Costin, Opere, éd. P.P. Panaitescu, Bucarest 1958, p. 96-99 ; V. Motogna, «Epoca lui Matei Basarab şi Vasile Lupu», Cerecetări istorice XIII-XVI (1940), p. 453-517 ; A.H. Golimaş, «Diplomatul Constantin Batişte Vevelli Rettimiotul şi revolựia Moldovei din primăvara anului 1633», Studii şi cercetări istorice 1 (1943), p. 1-19 ; C. Şerban, Vasile Lupu, Domn al Moldovei (1634-1653), Bucarest 1991, p. 46-48.

51. N. Iorga, «Vasile Lupu ca următor al împăraŢilor de răsărit în tutelarea Patriarhiei de Constantinopole şi a Bisericii Ortodoxe», Analele Academiei Române. Memoriile Secţiunii Istorice, II série, XXXVI (1913-1914), p. 207-235 ; Fr. Pall, «Les relations de Vasile Lupu avec l'Orient orthodoxe et particulièrement avec le Patriarcat de Constantinople, envisagées surtout d'après les lettres de Ligaridis ", Balcania VIII (1945), p. 66-140.

52. Voir les témoignages réunis dans L. Cotovanu, «Le diocèse de Dryinoupolis ", art. cit., p. 240-257.

53. M. Costin, op. cit., p. 98. Pour Paul d'Alep, qui a rédigé le récit de son voyage dans les Principautés, en arabe, Vasile Lupu était un «al-Rum », à savoir un Romain/Grec : Călători străini despre Ţările române, VI, Paul de Alep, éd. M.M. Alexandrescu-Dersca Bulgaru, M.A. Mehmet, Bucarest 1976, p. 87 et n. 423.

54. Gheorghe ştefan (1653-1657) a commencé son règne, tout comme Vasile Lupu en son temps, par la persécution des «Grecs » qui avaient fait carrière et fortune auprès du voïévode déchu. Divers types de sources indiquent que les persécutions ont visé toute la «maison » de Vasile Lupu et son entourage politique rempli de «Grecs ", persécutions qui se sont répercutées aussi sur les marchands : Călători străini, vI, p. 91-101; P. Zahariuc, Ţara Moldovei în vremea lui Gheorghe ştefan voievod (1653-1658), Jassy 2003, p. 113-118, 160, 187, 196-197 ; R. Păun, Pouvoirs, offices et patronage dans la Principauté de Moldavie au XVII siècle. L'aristocratie roumaine et la pénétration gréco-levantine, Thèse de doctorat, École des Hautes Études en Sciences sociales, Paris 2003, inédite, p. 483-485. 55. Sujet peu étudié jusqu'à ce jour. Un chapitre de ma thèse de doctorat en préparation lui est consacré. Le lecteur trouvera des considérations utiles chez B. Murgescu, 'Phanariots' and 
'Pământeni'. Religion and Ethnicity in Shaping Identities in the Romanian Principalities and the Ottoman Empire", dans Ethnicity and Religion in Central and Eastern Europe, éd. Maria Crăciun, O. Chitta, Cluj 1995, pp. 196-204 (version roumaine dans idem, Ţările române între Imperiul Otoman şi Europa creştină, Jassy 2012, p. 53-59.

\section{RÉSUMÉS}

La présente étude fait le point sur la géographie de l'émigration sud-danubienne vers la Valachie et la Moldavie des $\mathrm{XV}^{\mathrm{e}}-\mathrm{XVII}^{\mathrm{e}}$ siècles, en mobilisant une importante quantité de données prosopographiques et anthroponymiques. Il y est montré que, contrairement à d'anciens préjugés historiographiques, les vagues d'émigration sud-slave n'ont pas cessé de couler vers le nord du Danube après la disparition des anciennes noblesses balkaniques, dont la noblesse serbe qui s'est éclipsée dans la première moitié $d u x^{e}{ }^{e}$ siècle. On constate également que l'immigration communément appelée "grecque» arrivait de régions sud-danubiennes d'une relative proximité, l'espace d'origine des migrants dépassant rarement la Macédoine, à l'est, et la Thessalie, au sud. L'enquête met en lumière une forte concentration de migrants originaires d'Épire et des régions proches. L'espace levantin (îles égéennes et ioniennes) et l'espace constantinopolitain sont beaucoup moins représentés, comparés aux régions continentales de langue grecque. La répartition géographique des espaces d'origine des migrants correspond parfaitement à celle des donations religieuses (princières et privées) provenant de Valachie et de Moldavie pendant la période étudiée, ce qui conforte les résultats de mon enquête. Elle correspond également à la géographie des espaces dont les populations chrétiennes ont bénéficié d'une autonomie administrative et judiciaire de la part des sultans, autonomie qui devait conférer aux bénéficiaires (et surtout aux hommes célibataires) une certaine liberté de déplacement à travers l'espace de souveraineté ottoman et au-delà de ses limites, y compris dans les provinces nord-danubiennes dépendantes de la Porte. Il se trouve que parmi les populations qui jouissaient de tels privilèges collectifs figuraient maintes communautés régies par l'ancien droit coutumier valaque (jus valachicum), certaines attachées à l'orthodoxie de langue grecque et d'autres à celle de langue slavonne. D'où l'on déduit qu'une bonne partie des sujets ottomans installés dans les Principautés de Valachie et de Moldavie devaient être des Valaques (connus, d'ailleurs, pour avoir étendu leurs réseaux de commerce vers les grandes villes de l'empire des Habsbourg, au XVIII ${ }^{\mathrm{e}}$ siècle). Le tout porte à conclure qu'on a affaire à des migrants originaires de régions où le multilinguisme était à l'ordre du jour, qu'ils avaient pour caractéristique le fait de partager des appartenances collectives (spatiales et linguistiques ou culturelles plus généralement) multiples. Pareille constatation ouvre de nouvelles perspectives de recherche et d'interprétation quant aux représentations sociales des différences culturelles et des comportements identitaires individuels, à une époque où l'on est encore loin du principe politique de la souveraineté des peuples.

The study focuses on geographical distribution of the emigration oriented to Walachia and Moldova in the South-Danubian region in 15-17th centuries, which was established based on vast prosopographic and anthroponymic research. It shows that contrary to the long-lasting historiographic prejudices, the waves of South Slavic emigration did not stopped flowing to the north of the Danube after the disappearance of the old Balkan nobility, particularly Serbian, which was overshadowed during the first half of the $16^{\text {th }}$ century. The research also points out 
that immigration commonly called "Greek" came from relatively close South-Danubian regions; meaning that the area of origin of immigrants rarely exceeded Macedonia on the East and Thessaly on the South. The survey data reveal a high concentration of migrants from Epirus and its surroundings. The Levantine area (Aegean and Ionian Islands) and that of Constantinople are much less represented compared to the Greek mainland. The geographical distribution of migrants' homeland areas perfectly matches the distribution of religious donations (princely and private) coming from Wallachia and Moldova for South-Danubian religious institutions in that period, which confirms the results of the survey. It also corresponds to the geography of the places in which the Christian population enjoyed administrative and judicial autonomy from the Ottomans, which must have given to the population (specially single men) a certain freedom of movement within the Ottoman Empire and beyond its limits, including dependent NorthDanubian provinces of the Porte. Among those who enjoyed such privileges there were numerous communities governed by the old Wallachian customary law (jus valachicum), some of them attached to the Greek-speaking Orthodoxy and others to Slavonic language one. Henceforth, it is justified to assume that a large number of Ottoman dependants settled Wallachia and Moldavia were Vlachs (known, particularly, for expansion of their trade networks to major cities of the Empire Habsburg, in the 18th century). All mentioned geographical correlations lead to the conclusion that we are dealing with migrants from areas where multilingualism was the order of the day and consequently they had to have shared appurtenance to several collectivities (spatial and linguistic, or cultural, generally speaking). This finding opens new avenues for research and interpretation of social representations of collective cultural differences and behavioral identity of the individuals at the time much before the political principle of peoples' sovereignty.

\section{INDEX}

motsclestr Göç, Nüfusun göç, Buğdan, Eflak, Makedonya, Ulah, Romanya'da, On altıncı yüzyıl, On sekizinci yüzyıl, On dokuzuncu yüzyıl, Osmanlı İmparatorluğu, Demografi, Tarihsel coğrafya

Mots-clés : émigration, diaspora grecque, Valaques

Keywords : Emigration, Population migrations, Moldova, Wallachia, Macedonia, Vlachs, Greek diaspora, Sixteenth century, Ottoman Empire, Eighteenth century, Historical geography

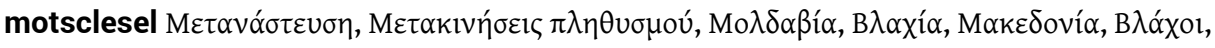

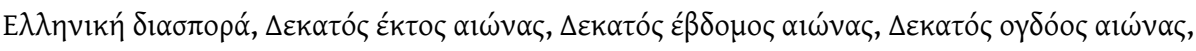

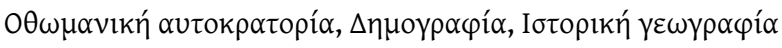

Index géographique : Moldavie, Valachie, Macédoine

Thèmes : Démographie, Géographie historique

motsclesmk ЕМИГРАЦИЈА, ПОМЕСТУВАњЕ, МОЛДАВИЈА, ВЛАШКО, МАКЕДОНИЈА, ВЛАШКИ, ГРЧКАТА ДИЈАСПОРА, ВЛАСИ, ШЕСНАЕСЕТТИОТ ВЕК, СЕДУМНАЕСЕТИОТ ВЕК, ОСУМНАЕСЕТТИОТ ВЕ, ОТОМАНСКАТА ИМПЕРИЈА, ДЕМОГРАФИЈАТА, ИСТОРИСКИ ГЕОГРАФИЈА

Index chronologique : Empire ottoman, dix-septième siècle, dix-huitième siècle

\section{AUTEUR}

LIDIA COTOVANU

EHESS - Paris 